\title{
ISKO News
}

\section{Edited by Hanne Albrechtsen}

\author{
Communications Editor
}

\section{KO Literature now searchable online}

Since its foundation, ISKO has been producing bibliographical bulletins of the literature published in the field of knowledge organization (KO). These followed Dahlberg's major International Classification and Indexing Bibliography, in two volumes covering years 1950-1982, with subsequent additions. The KO Literature bulletins, compiled by the knowledgeable and patient work of their editors Ingetraut Dahlberg, then (1997-2006) Gerhard Riesthuis, then (2007-present) Ia McIlwaine, were published regularly within this journal.

Since 2009, ISKO decided that the bulletins would be moved to a digital format and be available freely through our website <www.isko.org/lit.html >. This allowed prof. McIlwaine to start feeding a structured bibliographical database, set up in 2010 by me as the new webmaster, instead of formatted text files.

The structure of bibliographical records in the database reproduced that of records in the past bulletins, in view of interoperability with the back data. Thus, each record includes an identifier (originally counted from 1 onwards each year, then from 1 without any reset since the bulletins have moved online) and a classmark based on Dahlberg's classification of KO Literature (Knowledge Organization, 20 (1993), n. 4, p. 211-222; republished at <www.isko.org/scheme.php>, 2011) which applies the principles of her Systematifier.

Although this classification scheme was conceived several decades ago, thus needs some adaptations in order to class contemporary topics, its continued use of for quite a long time is a huge advantage as it offers the potential for unified subject search. Enabling easy access to consistent bibliographical information in our field can promote the knowledge of its valuable heritage on a wider basis, especially among different communities of researchers dealing with related although traditionally separated topics, each getting more and more relevant for the others in our telematic era.

With this idea in mind, I have started to look for possibilities of converting back data so to upload them to the database. An agreement between Ergon-Verlag and ISKO presidency allows us to make them freely available in our website. Digital versions of the past bul- letins from 1997 to 2008 have been kindly provided by their editors. After some consideration of possible solutions, a skilled collaborator has been identified in Pietro Fezzardi, student in Mathematics at the University of Pavia, who has been charged by ISKO of the data analysis and conversion work. This stage has been completed successfully last April, and the data have been uploaded in the database and merged with the current ones.

Since May 2012, the KO Literature section of our website allows for multi-field search in the integrated database from 1997 to present. Records can be extracted by class, author, word in title, year, and language. These fields can be combined creatively in order to get from a broad sample such interesting information as: how many papers on UDC in French vs. in Spanish are recorded, by comparison to the same ratio for papers on thesauri?

As some members had rightly remarked, the classmark for each record was not too useful as long as it was displayed without its verbal meaning -- a fact that we as knowledge organizers are even more aware of than our users. While in printed bulletins it would have been complex to show this information for layout and space reasons, in the Web environment this is now possible. So the classmarks are now automatically parsed by a PHP script, fitting the syntactical features of the Systematifier-based scheme for KO, which allows for synthesizing notation in several ways. The verbal headings of the corresponding isolates are thus identified in an almost perfect way, and displayed in dark orange colour on the top-right corner of each record, from where they can be selected for further navigation by subject.

No doubt, details of both data themselves and the search and display interface can be further improved. KO researchers are encouraged to spread the news of their availability, to try it and to report problems and suggestions to webmaster@isko.org

Let's hope that this service, building on the work of past and present compilers, will be only the start of a successful international database of $\mathrm{KO}$ literature.

Claudio Gnoli

gnoli@aib.it 


\title{
KNOWLEDGE ORGANIZATION
}

\author{
Official Bi-Monthly Journal of the International Society for Knowledge Organization \\ ISSN $0943-7444$ \\ International Journal devoted to Concept Theory, Classification, Indexing and Knowledge Representation
}

\author{
Publisher \\ ERGON-Verlag GmbH, Keesburgstr. 11, D-97074 Würzburg \\ Phone: +49 (0)931 280084; FAX + 49 (0)931 282872 \\ E-mail: service@ergon-verlag.de; http://www.ergon-verlag.de
}

\section{Editor-in-chief (Editorial office)}

Dr. Richard P. SMIRAGLIA (Editor-in-Chief), School of Information Studies, University of Wisconsin, Milwaukee, Northwest Quad Building B, 2025 E Newport St., Milwaukee, WI 53211 USA. E-mail: smiragli@uwm.edu

\section{Instructions for Authors}

Manuscripts should be submitted electronically (in Word or RTF format) in English only via email to the editor-in chief and should be accompanied by an indicative abstract of 100 to 200 words.

A separate title page should include the article title and the author's name, postal address, and E-mail address, if available. Only the title of the article should appear on the first page of the text.

To protect anonymity, the author's name should not appear on the manuscript, and all references in the body of the text and in footnotes that might identify the author to the reviewer should be removed and cited on a separate page. Articles that do not conform to these specifications will be returned to authors.

Criteria for acceptance will be appropriateness to the field of the journal (see Scope and Aims), taking into account the merit of the contents and presentation. The manuscript should be concise and should conform as much as possible to professional standards of English usage and grammar. Manuscripts are received with the understanding that they have not been previously published, are not being submitted for publication elsewhere, and that if the work received official sponsorship, it has been duly released for publication. Submissions are refereed, and authors will usually be notified within 6 to 10 weeks.

The text should be structured by numbered subheadings. It should contain an introduction, giving an overview and stating the purpose, a main body, describing in sufficient detail the materials or methods used and the results or systems developed, and a conclusion or summary.

Footnotes are not permitted; all narration should be included in the text of the article.

Italics should not be used for emphasis. Em-dashes should be used as substitutes for commas. Paragraphs should include a topic sentence and some developed narrative. A typical paragraph has several sentences.

Reference citations within the text should have the following form: (author year). For example, (Jones 1990). Specific page numbers are required for quoted material, e.g. (Jones 1990, 100). A citation with two authors would read (Jones and Smith, 1990); three or more authors would be: (Jones et al., 1990). When the author is mentioned in the text, only the date and optional page number should appear in parenthesis - e.g. According to Jones (1990), ...

References should be listed alphabetically by author at the end of the article. Author names should be given as found in the sources (not abbreviated). Journal titles should not be abbreviated.
Multiple citations to works by the same author should be listed chronologically and should each include the author's name. Articles appearing in the same year should have the following format: "Jones 2005a, Jones 2005b, etc." Issue numbers are given only when a journal volume is not through-paginated.

Examples:

Dahlberg, Ingetraut. 1978. A referent-oriented, analytical concept theory for INTERCONCEPT. International classification 5: $142-51$.

Howarth, Lynne C. 2003. Designing a common namespace for searching metadata-enabled knowledge repositories: an international perspective. Cataloging E classification quarterly $37 \mathrm{n} 1 / 2$ : 173-85.

Pogorelec, Andrej and Šauperl, Alenka. 2006. The alternative model of classification of belles-lettres in libraries. Knowledge organization 33: 204-14.

Schallier, Wouter. 2004. On the razor's edge: between local and overall needs in knowledge organization. In McIlwaine, Ia C. ed., Knowledge organization and the global information society: Proceedings of the Eighth International ISKO Conference 13-16 July 2004 London, UK. Advances in knowledge organization 9. Würzburg: Ergon Verlag, pp. 269-74.

Smiraglia, Richard P. 2001. The nature of 'a work': implications for the organization of knowledge. Lanham, Md.: Scarecrow.

Smiraglia, Richard P. 2005. Instantiation: Toward a theory. In Vaughan, Liwen, ed. Data, information, and knowledge in a networked world; Annual conference of the Canadian Association for Information Science ... London, Ontario, June 2-4 2005. Available http://www.cais-acsi.ca/2005proceedings.htm.

Illustrations should be kept to a necessary minimum and should be embedded within the document. Photographs (including color and half-tone) should be scanned with a minimum resolution of $600 \mathrm{dpi}$ and saved as .jpg files. Tables and figures should be embedded within the document. Tables should contain a number and title at the bottom, and all columns and rows should have headings. All illustrations should be cited in the text as Figure 1, Figure 2, etc. or Table 1, Table 2, etc.

Upon acceptance of a manuscript for publication, authors must provide a wallet-size photo and a one-paragraph biographical sketch (fewer than 100 words). The photograph should be scanned with a minimum resolution of $600 \mathrm{dpi}$ and saved as a .jpg file.

\section{Advertising}

Responsible for advertising: ERGON-Verlag GmbH, Keesburgstr. 11, 97074 Würzburg (Germany).

(C) 2012 by ERGON-Verlag GmbH.

All Rights reserved.

KO is published bi-monthly by ERGON-Verlag GmbH.

- The price for the print version is $€ 198,00$ /ann. including airmail delivery.

- The price for the print version plus access to the online version (PDF) is $€ 229,00 / a n n$. including airmail delivery. 


\title{
$\mathrm{KO}$
}

\section{KNOWLEDGE ORGANIZATION}

\author{
Official Bi-Monthly Journal of the International Society for Knowledge Organization \\ ISSN $0943-7444$ \\ International Journal devoted to Concept Theory, Classification, Indexing and Knowledge Representation
}

\section{Scope}

The more scientific data is generated in the impetuous present times, the more ordering energy needs to be expended to control these data in a retrievable fashion. With the abundance of knowledge now available the questions of new solutions to the ordering problem and thus of improved classification systems, methods and procedures have acquired unforeseen significance. For many years now they have been the focus of interest of information scientists the world over.

Until recently, the special literature relevant to classification was published in piecemeal fashion, scattered over the numerous technical journals serving the experts of the various fields such as:

\author{
philosophy and science of science \\ science policy and science organization \\ mathematics, statistics and computer science \\ library and information science \\ archivistics and museology \\ journalism and communication science \\ industrial products and commodity science \\ terminology, lexicography and linguistics
}

Beginning in 1974, KNOWLEDGE ORGANIZATION (formerly INTERNATIONAL CLASSIFICATION) has been serving as a common platform for the discussion of both theoretical background questions and practical application problems in many areas of concern. In each issue experts from many countries comment on questions of an adequate structuring and construction of ordering systems and on the problems of their use in opening the information contents of new literature, of data collections and survey, of tabular works and of other objects of scientific interest. Their contributions have been concerned with

(1) clarifying the theoretical foundations (general ordering theory/science, theoretical bases of classification, data analysis and reduction)

(2) describing practical operations connected with indexing/classification, as well as applications of classification systems and thesauri, manual and machine indexing

(3) tracing the history of classification knowledge and methodology

(4) discussing questions of education and training in classification

(5) concerning themselves with the problems of terminology in general and with respect to special fields.

\section{Aims}

Thus, KNOWLEDGE ORGANIZATION is a forum for all those interested in the organization of knowledge on a universal or a domain-specific scale, using concept-analytical or concept-synthetical approaches, as well as quantitative and qualitative methodologies. KNOWLEDGE ORGANIZATION also addresses the intellectual and automatic compilation and use of classification systems and thesauri in all fields of knowledge, with special attention being given to the problems of terminology.

KNOWLEDGE ORGANIZATION publishes original articles, reports on conferences and similar communications, as well as book reviews, letters to the editor, and an extensive annotated bibliography of recent classification and indexing literature.

KNOWLEDGE ORGANIZATION should therefore be available at every university and research library of every country, at every information center, at colleges and schools of library and information science, in the hands of everybody interested in the fields mentioned above and thus also at every office for updating information on any topic related to the problems of order in our information-flooded times.

KNOWLEDGE ORGANIZATION was founded in 1973 by an international group of scholars with a consulting board of editors representing the world's regions, the special classification fields, and the subject areas involved. From 1974-1980 it was published by K.G. Saur Verlag, München. Back issues of 1978-1992 are available from ERGON-Verlag, too.

As of 1989, KNOWLEDGE ORGANIZATION has become the official organ of the INTERNATIONAL SOCIETY FOR KNOWLEDGE ORGANIZATION (ISKO) and is included for every ISKO-member, personal or institutional in the membership fee (US \$ 55/US \$ 110).

Rates: From 2011 on for 6 issues/ann. (including indexes) $€ 198,00$ (forwarding costs included) for the print version resp. $€ 229,00$ for the print version plus access to the online version (PDF). Membership rates see above.

ERGON-Verlag GmbH, Keesburgstr. 11, D-97074 Würzburg; Phone: +49 (0)931 280084; FAX +49 (0)931 282872; E-mail: service@ergon-verlag.de; http://www.ergon-verlag.de

The contents of this journal are indexed and abstracted in Referationyi Zhurnal Informatika and in the following online databases: Information Science Abstracts, INSPEC, Library and Information Science Abstracts (LISA), Library Literature, PASCAL, Sociological Abstracts, and Web Science E Social Sciences Citation Index. 